\title{
Time-Dependent Post-Peak Softening of RC Members in Flexure
}

\author{
Khaled Farouk El-Kashif ${ }^{1}$ and Koichi Maekawa ${ }^{2}$
}

Received 7 December 2003, accepted 22 July 2004

\begin{abstract}
To investigate the rate effects on post-peak structural behavior accompanying the compression softening of structural concrete, experimental studies were carried out on over-reinforced concrete beams with and without confinement under varied rates of flexural loading. The effects of loading rate on the capacity and ductility of RC beams were found more pronounced in confined cases than unconfined cases. The generic time-dependent constitutive model of compression-softened concrete was applied to nonlinear collapse analysis and its applicability was verified by experiments. The strain rate in the compressive localized zone in structures rapidly increased after the member reached its peak capacity even though the rate of displacement was kept unchanged especially in the case of unconfined beams. In the case of confined RC beams, localization of weak strain occurred but with comparatively greater time-dependent plasticity and fracturing within the structure. These deformation characteristics were adequately simulated by nonlinear analysis using a time-dependent constitutive model for softened concrete in compression.
\end{abstract}

\section{Introduction}

In the past two decades, much effort has been made for the modeling of reinforced concrete (RC) from the viewpoint of nonlinear mechanics of cracking, steel yielding and their interactions. The knowledge thus acquired has been translated into codified software for the numerical simulation of structural responses. It should be noted that some fruits of research in RC nonlinear mechanics are currently yielding engineering benefits in performance based design, particularly seismic resistant design, where structural plasticity and damage allowances provide considerable cost benefits.

Given that the reliability of computational results depends largely on the versatility of the material models used, careful verification has been conducted. Here, the time dependency of the constitutive laws of concrete has explicitly been taken into account as a creep problem under long-term service loads. On the other hand, time dependency has implicitly been treated through the formulation of a stress-strain relationship under specific rates of stress or strain for the ultimate limit state under extreme loads (Okamura et al. 1991). This simplified way to consider instant time dependency is practical and usually allows for reasonable simulation up to the peak structural capacity. Implicit here is the assumption that the strain rates within structural concrete are nearly constant and proportional to the rates of external loading. This assumption may practically hold up to the peak structural capacity especially in statically determinate

${ }^{1}$ Post Doctoral Fellow, Department of Civil Engineering The University of Tokyo, Japan.

${ }^{2}$ Professor, Department of Civil Engineering, The University of Tokyo, Japan.

E-mail: maekawa@concrete.t.u-tokyo.ac.jp structures, and the effects are not so predominant on the stress-strain relationship in nature except for shock/impact loads.

However, it is a different story in the case of concrete that is softened after reaching the peak capacity. The post-peak stress-strain relationship is largely time-dependent in nature. As a post-peak response accompanies the localization of compression, the strain rate at a certain limited volume in structures will be non-uniformly accelerated even though the loading rate is kept constant or low. Thus, collapse analysis requires consideration of time dependency for post-peak compression softening (El-Kashif et al. 2003, 2004). Here, it is not clear whether we can use constant strain rate modeling for collapse analysis. In most cases nowadays, the softened stress-strain relationship is employed without considering time dependency, regardless of how fast stress decreases during the softening process.

In this study, the authors apply a generic time-dependent constitutive model for compression-softened concrete to collapse analysis, aiming to investigate the rate effects on post-peak structural mechanics. Experiments on displacement-controlled RC beams are presented, and the direct time-integral analysis of collapsing structural concrete is discussed as a strategic way to analyze the post-peak process under extreme loads.

\section{Time dependent softening of RC beams in flexure}

\subsection{Experiment}

The purpose of the experiment was to investigate the time dependency of post-peak softened RC members with compressive localization and obtain important data for benchmark collapse analysis. To accomplish it, the 
Table 1 Material composition.

\begin{tabular}{|c|c|c|c|c|c|}
\hline Concrete type & $\begin{array}{c}\text { Water/ } \\
\text { cement ratio** }\end{array}$ & $\begin{array}{c}\text { Cement } \\
(\mathrm{kg})\end{array}$ & $\begin{array}{c}\text { Sand } \\
(\mathrm{kg})\end{array}$ & $\begin{array}{c}\text { Coarse aggregate } \\
(\mathrm{kg}) *\end{array}$ & $\begin{array}{c}\text { Chemical admixture } \\
\left(\mathrm{mm}^{3}\right)\end{array}$ \\
\hline Normal Concrete & 0.5 & 352 & 866 & 890 & 440 \\
\hline
\end{tabular}

*) Maximum size of coarse aggregates: $20 \mathrm{~mm}$

**) Compressive strength upon testing: $34.5 \mathrm{MPa}$ (49 days after casting)

Table 2 Beam specimen details.

\begin{tabular}{|c|c|c|c|c|c|c|c|c|}
\hline \multirow{2}{*}{$\begin{array}{c}\text { Beam } \\
\text { notation }\end{array}$} & \multirow{2}{*}{$\begin{array}{l}\text { Loading } \\
\text { condition } \\
\text { (target) }\end{array}$} & \multirow{2}{*}{$\begin{array}{c}\text { Dimension } \\
\text { B-H-L } \\
(\mathrm{cm})\end{array}$} & \multicolumn{3}{|c|}{ (Stirrups) L1 } & \multicolumn{3}{|c|}{ (Stirrups) L2 } \\
\hline & & & $\mathrm{D}(\mathrm{mm})$ & $\begin{array}{c}\mathrm{S} \\
(\mathrm{cm})\end{array}$ & $\begin{array}{c}\mathrm{L} 1 \\
(\mathrm{~cm}) \\
\end{array}$ & $\begin{array}{c}\mathrm{D} \\
(\mathrm{mm})\end{array}$ & $\begin{array}{c}\mathrm{S} \\
(\mathrm{cm})\end{array}$ & $\begin{array}{c}\mathrm{L} 2 \\
(\mathrm{~cm}) \\
\end{array}$ \\
\hline Beam1 & $1.00 \mathrm{~mm} / \mathrm{min}$ & $15-30-270$ & 10 & 5 & 95 & - & - & 80.0 \\
\hline Beam2 & $0.15 \mathrm{~mm} / \mathrm{min}$ & $15-30-270$ & 10 & 5 & 95 & - & - & 80.0 \\
\hline Beam3 & $1.00 \mathrm{~mm} / \mathrm{min}$ & $15-30-270$ & 10 & 5 & 95 & 10 & 10 & 80.0 \\
\hline Beam4 & $0.15 \mathrm{~mm} / \mathrm{min}$ & $15-30-270$ & 10 & 5 & 95 & 10 & 10 & 80.0 \\
\hline
\end{tabular}

*) Yield strength of longitudinal reinforcement (D22) and stirrups (D10): $625 \mathrm{MPa}$ and $350 \mathrm{MPa}$, respectively.

**) Degree of confinement is quantified in section 3.2.

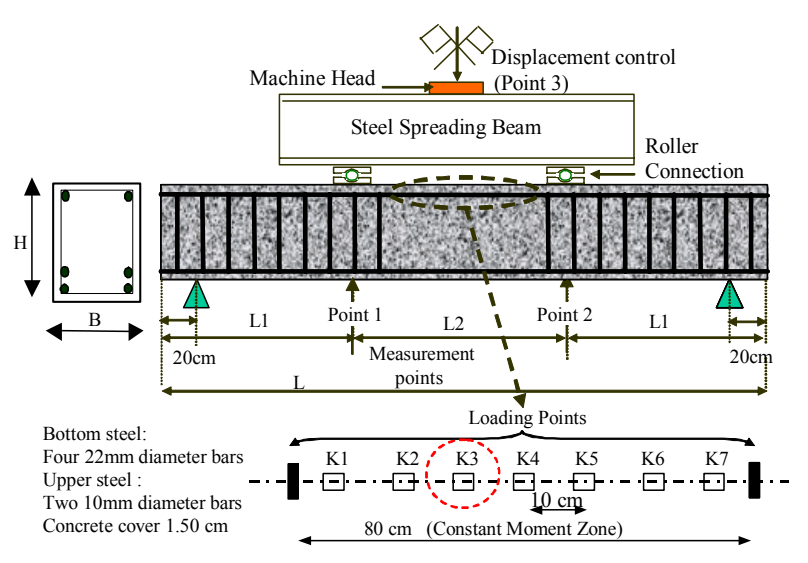

Fig. $1 \mathrm{RC}$ beam specimens.

authors used over-reinforced beams in flexure. The experiment was carried out under controlled loading with varied rates to confirm behavioral time dependency as well as the confinement effects on post-peak softening in specific terms.

The concrete mixture used in the experiment is shown in Table 1. Beam specimens underwent standard 28-day wet curing and where then exposed to room ambient conditions for another three weeks. Details of the beam specimens and testing conditions are shown in Table 2 and Fig. 1. In order to avoid shear failure, the shear mode capacity was designed to be 1.6 times greater than the flexural mode capacity.

A controlled displacement was induced for all the specimens. The beams were supported by two sliding-rollers that permitted free rotation and translation in the longitudinal direction. Two-point loading was applied as shown in Fig. 1, and displacement at each point was measured at regular time intervals. A pin-connected spreader beam was used for distributing force on the two loading points, and the same force was applied under pre- and post-peak conditions. Thus, there was no constraint on the loading system in terms of displacements. Two thick steel plates (25 by 100 by $250 \mathrm{~mm}$ ) were attached to the surface of the concrete to distribute the bearing stress of rollers to avoid the splitting of tension cracking above the supports and loading points.

Thirty-millimeter-long strain transducers were embedded in concrete over the constant moment zone to capture the localized region of compressive deformation. Gauges were placed $3.5 \mathrm{~cm}$ from the top extreme fiber at intervals of $10 \mathrm{~cm}$, as shown in Fig. 1. The displacements were recorded with an LVDT displacement transducer installed just beneath the loading points. As all the beams were expected to fail in flexural compression, a displacement control device featuring closed feedback was installed at Point 3 for stable equilibrium in the post-peak region, as shown in Fig. 1.

The experimental results are presented in the form of load-displacement diagrams and the strains of concrete at the compressive fiber. The main points of discussion are the loading rates and degree of confinement supplied by web reinforcement (Table 2) in the constant moment zone ( $L 2$ in Fig. 1). If the loading rate were so high as to provoke stress waves, the experimental verification of time-dependent plasticity and fracturing model would hardly be completed. Thus, experimental rates of loading were determined for verification so that time-dependent plasticity and fracturing would substantially develop in structural concrete during loading.

\subsection{Time-dependent displacement of RC beams 2.2.1 Unconfined RC}

Figure 2 shows the average shear force-displacement relationships for Beams 1 and 2. The displacements shown here are the average readings taken from points 1 and 2 (Fig. 1). Flexural cracks gradually propagated first and the mode of failure was flexural compression without yield of reinforcement. Then, the compressive mechanics of concrete became substantial. The low rate loading of $0.15 \mathrm{~mm} / \mathrm{min}$. at Point 3 slightly decreased the peak capacity and stiffness under conditions of higher stress. The high rate loading of $1 \mathrm{~mm} / \mathrm{min}$. elevated the peak capacity a little, but a more rapid reduction in residual force was observed after the peak. Be- 


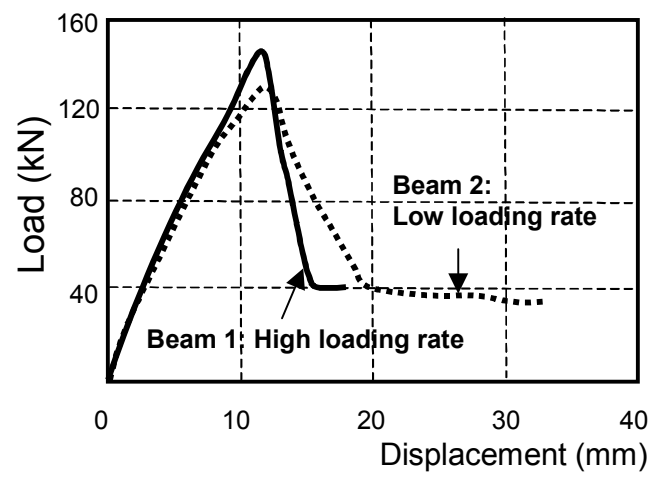

(a) Unconfined concrete

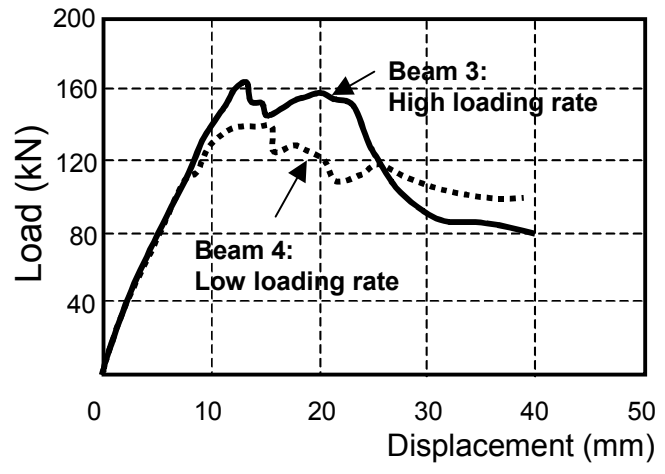

(b) Confined concrete

Fig. 2 Shear force-average displacement relationships.

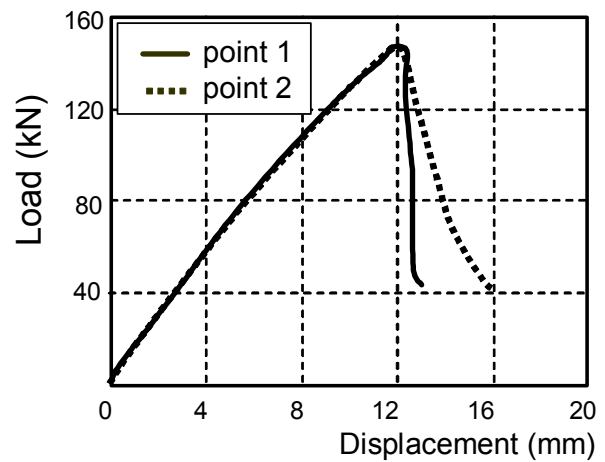

(a) Load versus displacement for Beam 1

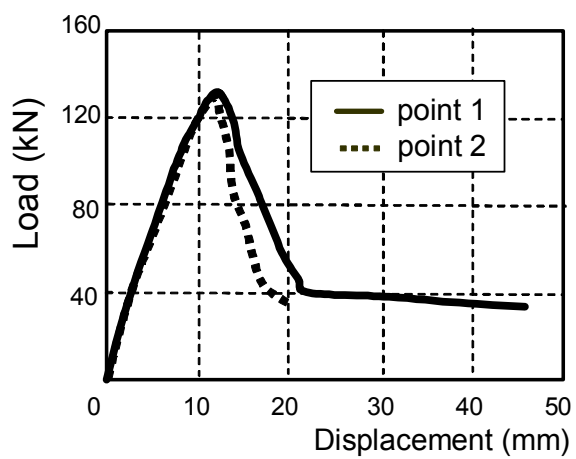

(c) Load versus displacement for Beam 2

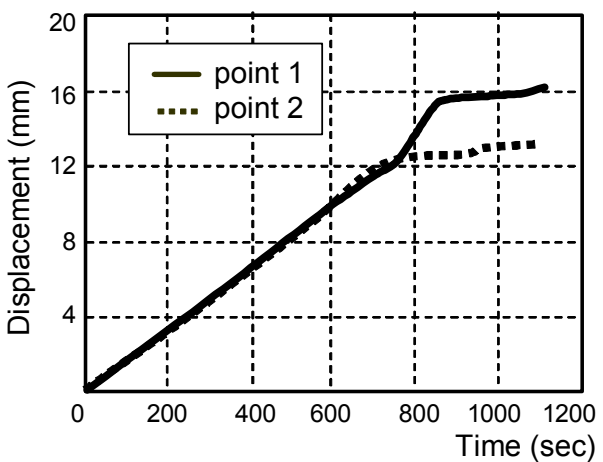

(b) Displacement versus time for Beam 1

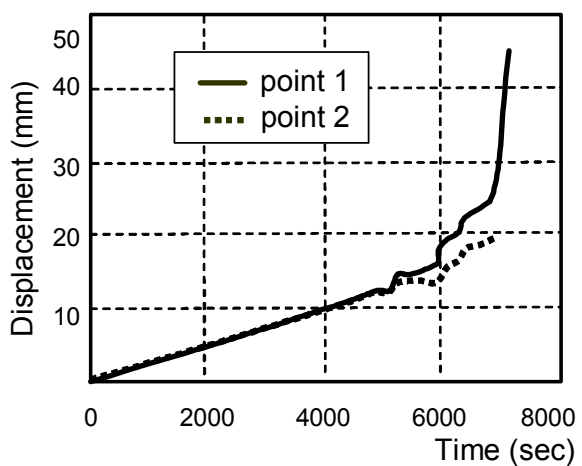

(d) Displacement versus time for Beam 2

Fig. 3 Load displacement relationships for Beams 1 and 2.

fore the peak capacity was reached, the same rates of stiffness and displacement were clearly detected at individual loading points of Beam 1, as shown in Fig. 3.

After the peak, the measured displacements of Points 1 and 2 started to deviate even though the same forces were produced since the damage state could not be perfectly symmetric, which shall be discussed later in section 2.3. In Beam 2, more stable displacements were observed after the peak load, which however showed a significant increment in an asymmetric manner, as shown in Fig. 3d.

On the whole, the time-dependent mechanics of RC beams were found to be similar to those of the concrete material. A higher strain rate applied to the plain concrete mass enhanced its concrete strength, showing a steep descending branch of a softened stress-strain curve. If the mode of failure had been flexural tension associated with yielding of reinforcement, the time-dependent characteristics would have been less pronounced because compressive deformational characteristics have almost nothing to do with flexural capacity.

\subsubsection{Confined RC}

Beams 3 and 4 represent cases where the concrete was confined in the constant moment zone at the span center. The effects of loading rates on confined beams are shown in Fig. 2. It is clear that confinement effectively improved ductility. Furthermore, there was greater similarity in time dependency in the post-peak responses. The individual load-displacement relationships are shown in Fig. 4. Almost the same rates of displace- 


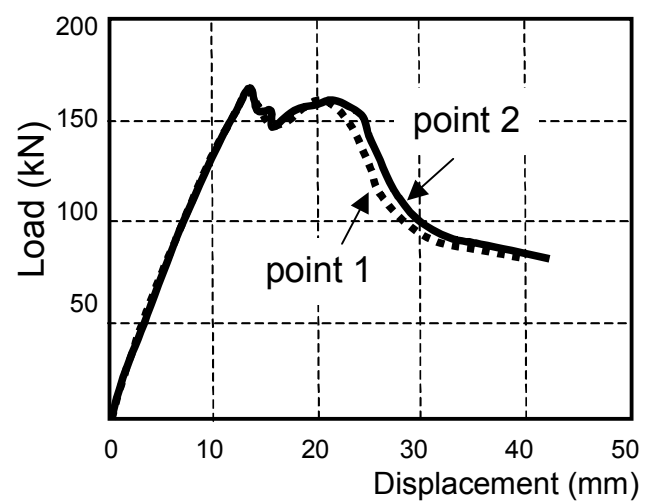

(a) Load versus displacement for Beam 3

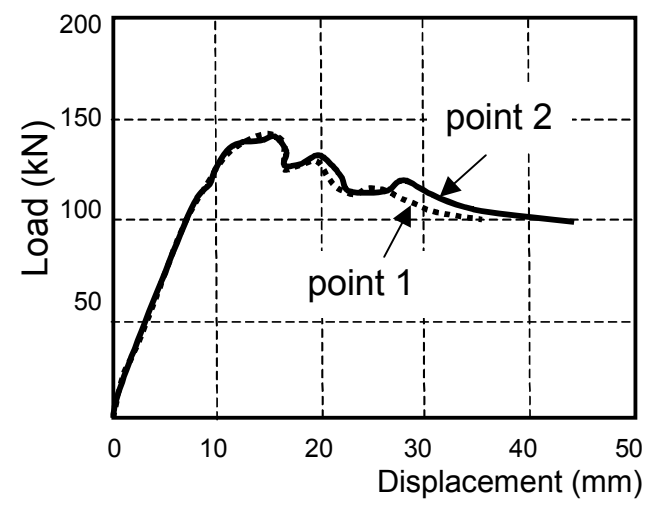

(c) Load versus displacement for Beam 4

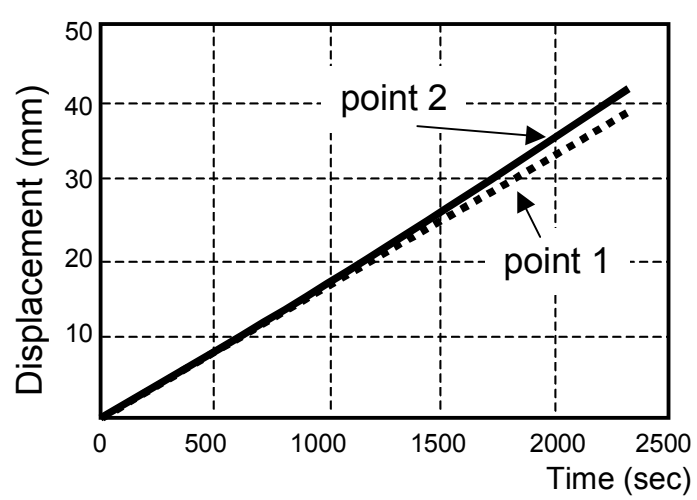

(b) Displacement versus time for Beam 3

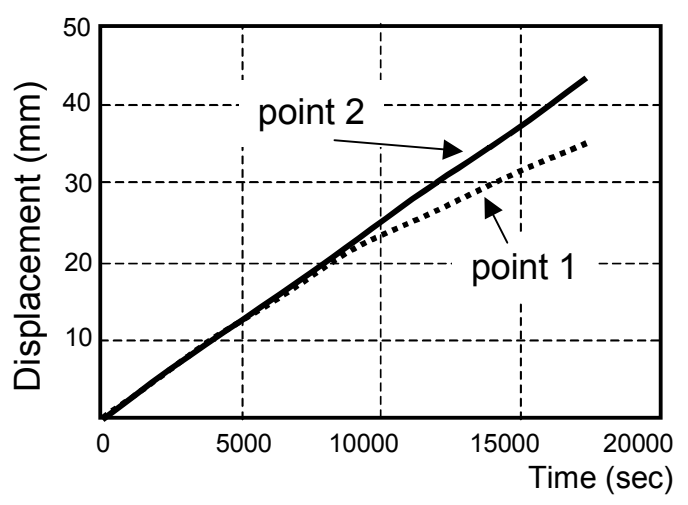

(d) Displacement versus time for Beam 4

Fig. 4 Load displacement relationships for Beams 3 and 4 .

ment developed at each loading point. Compared with unconfined RC members, the deformational field showed a more pronounced symmetrical form. The confinement increased stability and created more uniform strain fields even in the post-peak regions.

Lateral confinement by web reinforcement played an important role in improving the post-peak ductility in additional to loading rates, as outlined in Fig. 2. The mechanics of confined concrete have widely been investigated for high loading rate cases. General experimental observation revealed that the load carrying capacity was improved at both high and low loading rates. After the spalling of small concrete covers, the lateral ties continued to restrain the core concrete from further spalling. Cracks were found in the longitudinal direction along the compression steel, which was followed by large transverse displacement of reinforcing bars in the buckling mode in both Beams 1 and 2. Here, the buckling length was more or less the half the span length. On the other hand, the buckling length became short in confined beams. The enhancement of ductility in confined beams is thought to be attributable to the ductile characteristics of confined concrete and post-buckling steel stress, which depends on the spacing of stirrups. However, it can be stated that the time dependency of the confined beams was a result of the characteristics of the concrete since steel can be assumed to be time independent and the experimental buckling length was almost constant regardless of the loading rate.

\subsection{Damage Localization}

Alca et al. (1997), Jansen et al. $(1995,1997)$ and Weiss et al. (2001) showed that the portions adjacent to localized damage regions change to unloaded states after the peak. A similar deformational field can be observed in over-reinforced beams under flexure. Figure 5 shows the profile of strains measured with embedded gauges (gauge length $=3 \mathrm{~cm}$ ) and an overview of corresponding damage areas. Before reaching the peak capacity, the strain profile over the constant moment span was almost uniform. Just after the peak capacity, predominant strain localization developed. For unconfined Beams 1 and 2, the size of the strain localization areas was approximately $20 \mathrm{~cm}$ (Lettsrisakulrat et al. 2000). The localized size of Beam 2 subjected to low loading rates appeared to be slightly larger.

With regard to the confined RC beams, a localized zone appeared in the concrete too, but its size was definitely larger than the unconfined beams, and when a low rate of loading was applied, weak localization was observed. It can be concluded that the size of compressive localization is not constant but varies in accordance with confinement as well as the rate of loading. The maximum size of coarse aggregates, which may also affect the compressive localization size, was kept unchanged during the experiment.

Figure 6 shows the strain history of each location. In Beam 1, a drastic increase in strain was observed at point $K 6$, while the rest of the points showed decreases 

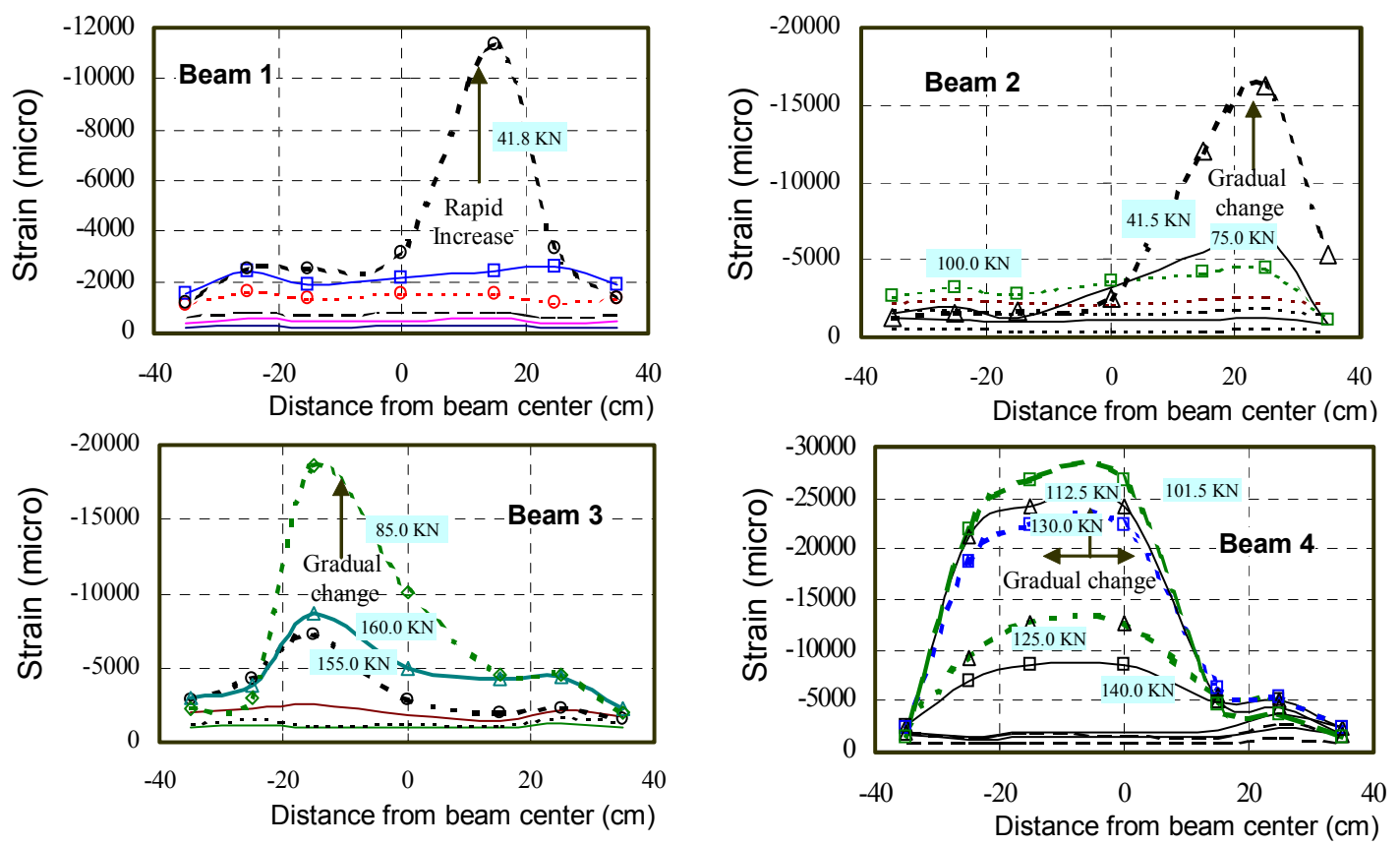

(a) Strain profiles of all beams
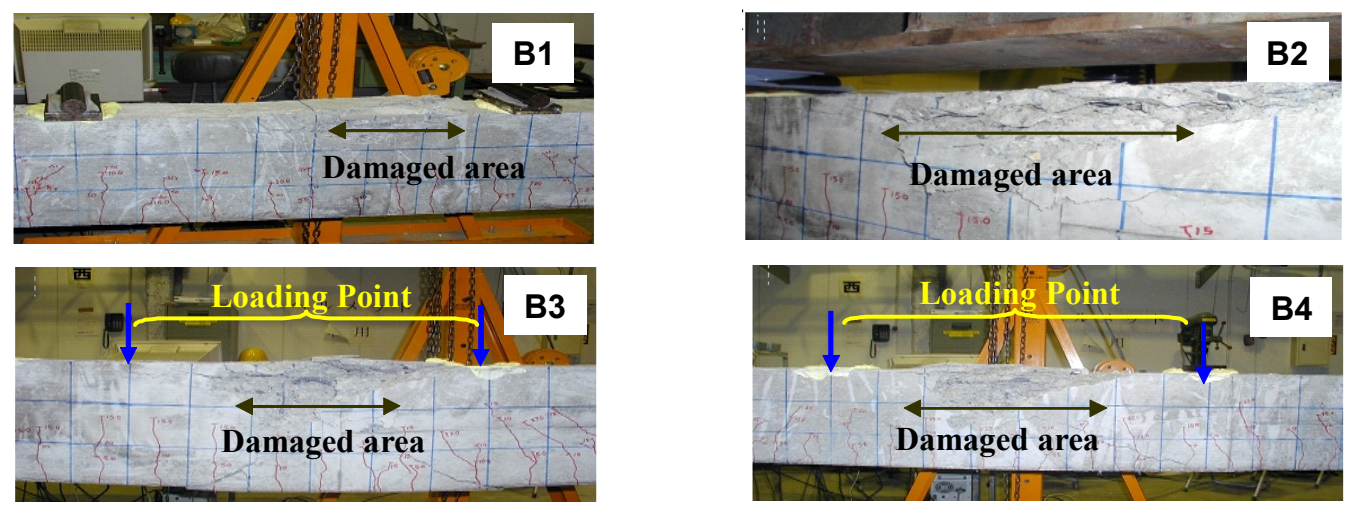

(b) Final damage pattern of all beams

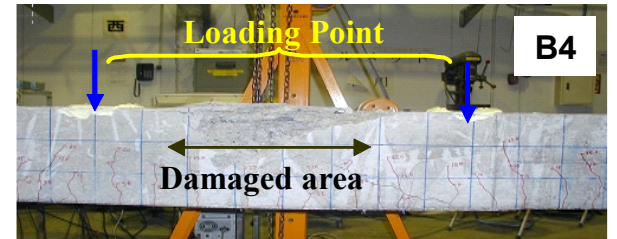

Fig. 5 Strain distributions along constant moment zone at $3.5 \mathrm{~cm}$ from top fiber and overview of damaged area.

in strain. For Beam 2, two locations denoted as $K 5$ and $K 6$ exhibited an increase in deformation with no setback.

Localization under a low rate of loading tended to weaken. It is certain that the strain rate was not constant but suddenly increased immediately after the concrete softened. Although confinement may have weakened the localization, a rapid increase in strain rate was also observed for the confined beams, a trend similar to that observed in unconfined members.

Figure 7 shows the relationship between the applied load and the local strain. Compared with the unconfined beams, greater residual force was maintained even though larger strains developed at the span center, which was laterally confined by web reinforcement. Some gauges indicated progressive strain after the peak even where no lateral confinement was provided (Beam 1). Nonetheless, when the rate of loading was high, only one gauge remained to demonstrate the evolution of strain. If under a low loading rate, a large magnitude of stress were continuously applied, the two gauges would finally have shown localization even though the residual force decreased to the stability of softening.

\section{Post peak collapse analysis}

\subsection{Scheme of computation}

To analyze the tested beams, the authors adopted the main frame of 2D nonlinear finite element analysis code WCOMD (Okamura et al. 1991). The multi-directional fixed crack model (Maekawa et al. 2003) for in-plane $\mathrm{RC}$ elements was the core technical aspect here. This constitutive modeling consisted of (1) concrete tension stiffening normal to cracks, (2) shear transfer based on a contact density model along cracks and (3) concrete compression parallel to cracks. These three sub-models had been developed for the computation of ultimate limit states, and time dependency was not explicitly included in the formulation. Thus, the authors replaced the original elasto-plastic and fracturing concrete model 

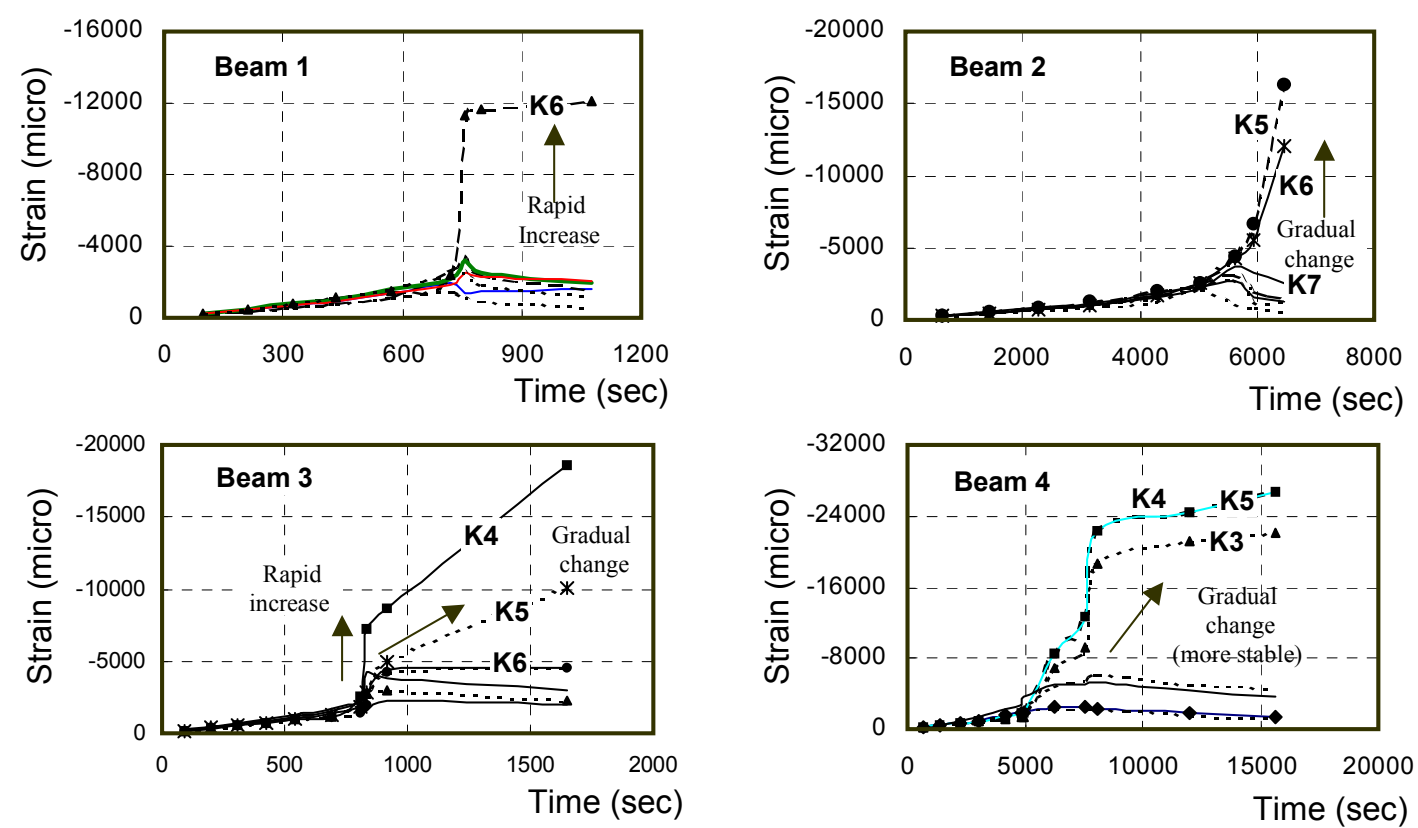

Fig. 6 Strain hysteresis at $3.5 \mathrm{~cm}$ from top fiber.
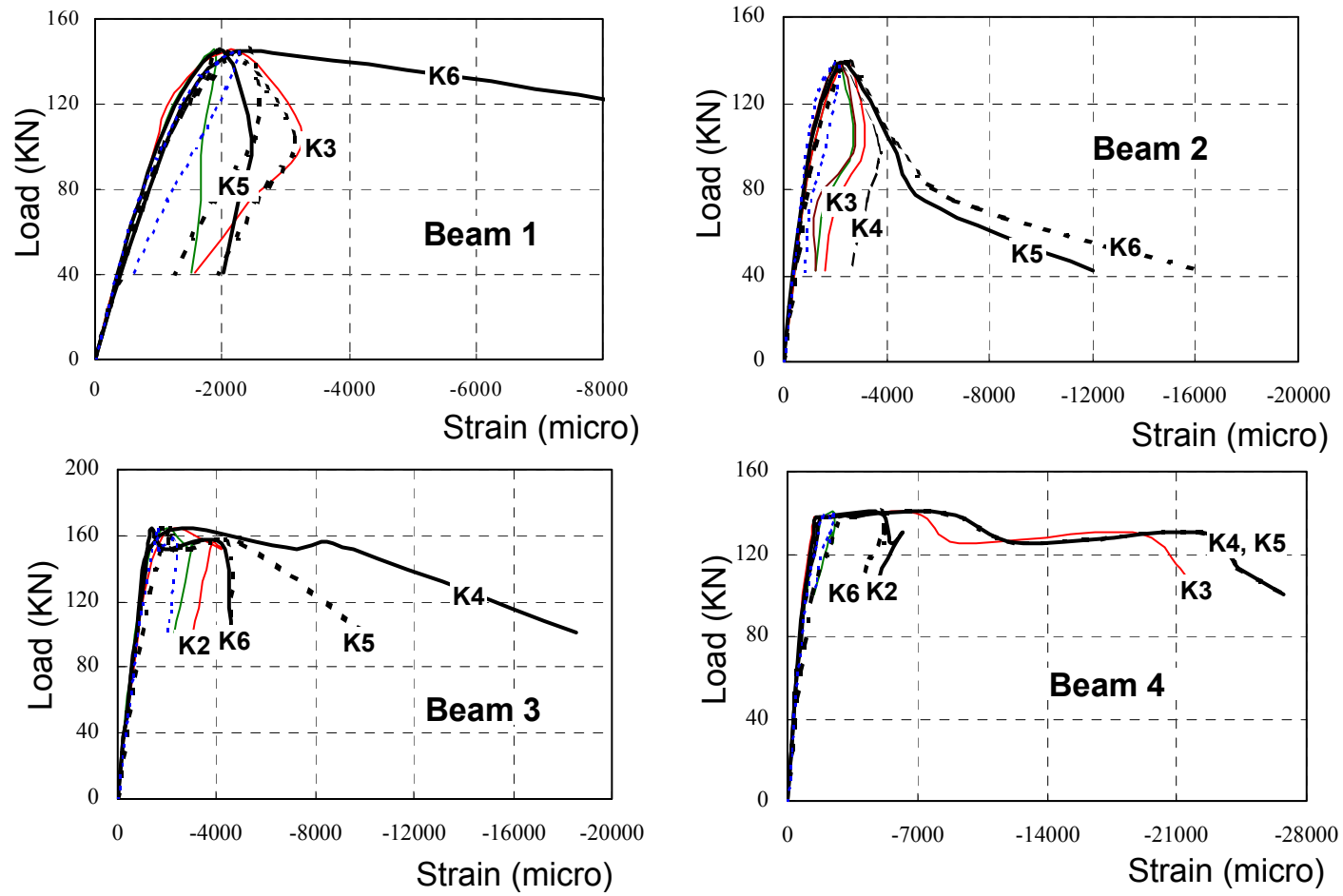

Fig. 7 Load-local strain relationship at $3.5 \mathrm{~cm}$ from top fiber.

with a newly proposed time-dependent constitutive model.

Since the nonlinear behavior of $\mathrm{RC}$ beams in flexure is hardly affected by shear transfer, time dependence can be ignored. Thus, the original contact density model (Okamura et al. 1991) was used without modifying the time-dependency aspect. Post-cracking tension stiffening models are known to be time-dependent and the deflection of RC beams is chiefly affected by post-cracking tension-stiffness modeling. However, it is recognized that the time dependency of tension stiffness is a factor of long-term RC creep deformation but negligible in the short-term collapse analysis. Thus, the authors used the original tension stiffness modeling for collapse simulation of the beams tested. Code WCOMD operates a reinforcing bar model applicable to the preand post-buckling situations (Dhakal et al. 2002, Maekawa et al. 2003). This model assumes a buckling length that is associated with lateral confinement by steel, and computes the average post-buckling stress-strain relationship according to the size of finite elements with consistent energy (Maekawa et al. 2004). 

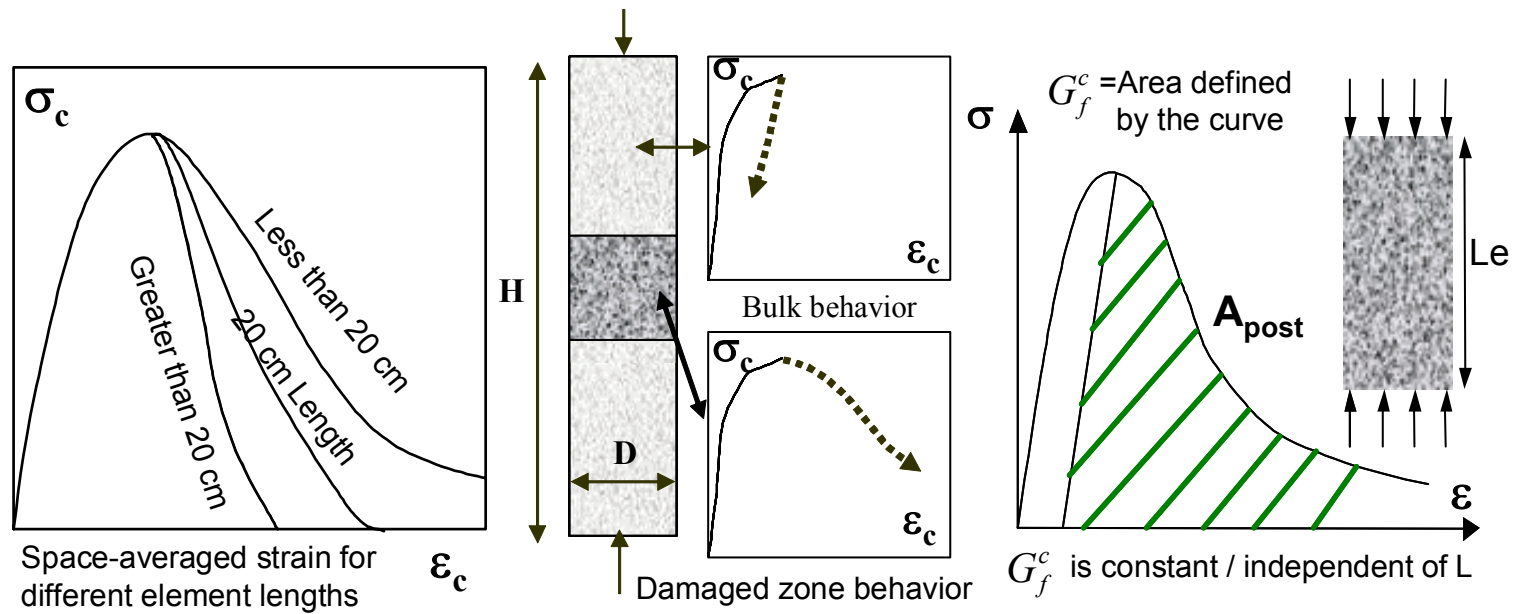

Fig. 8 Average stress-strain relationship associated with size of elements and compressive localization.

Time dependency was not taken into account for the reinforcing steel.

\subsection{Time-dependent concrete model}

For an immediate collapse analysis, the time-dependent elasto-plastic and damaging model developed by the present authors was applied to concrete compression.

With this model, the pre- and post-peak stress strain relationships are consistently explained through the coupling of elasto-plasticity with the continuum damage model (El-Kashif et al. 2003), which is given by

$$
\begin{aligned}
\sigma(t) & =E_{o} K\left(\varepsilon_{e}(t), \varepsilon_{e}(\tau: \tau<t)\right) \\
& \cdot\left\{\varepsilon-\varepsilon_{p}\left(\varepsilon_{e}, \varepsilon_{e}(\tau: \tau<t)\right)\right\}
\end{aligned}
$$

where, $K$ : fracture parameter, $\varepsilon_{\mathrm{p}}$ : plastic strain, and $\varepsilon_{\mathrm{e}}$ : elastic strain.

The plasticity and damage denoted by $\varepsilon_{\mathrm{p}}$ and $K$, respectively, were formulated in terms of updated elastic strain $\varepsilon_{\mathrm{e}}(\mathrm{t})$ as well as its past history $\varepsilon_{\mathrm{e}}(\tau: \tau<\mathrm{t})($ El-Kashif et al. 2003).

Any constitutive model explains a space-averaged stress-strain relationship on the referential volume (REV) on which field averaging is conducted. The size of REV of the base model (El-Kashif et al. 2003) is set at $20 \mathrm{~cm}$ (Lettsrisakulrat et al. 2000). If this model is applied to finite elements whose size coincides with that of REV, the material model and structural analysis represent the consistency of fracture energy in compression.

However, if the original constitutive model (El-Kashif et al. 2003) is applied to larger size finite elements as shown in Fig. 8 for example, physical inconsistency may be observed in the post-peak softening states. In reality, the uniformity assumption for the strain field is violated inside the finite element under a uniform stress field. The compressive localized volume develops within a larger finite element while the rest of the volume turns to the unloaded states. When the space-averaging procedure is applied for the size of large finite element, the average stress-strain relation- ship on the finite element subjected to uniform stress becomes different from the specified-REV-based relationship. In general, the average stress-strain relationship defined on the large finite element shows a sharp decrease in residual stress, as shown in Fig. 8. When using a smaller finite element, we have the opposite drift of the curve. In this case, some mechanics-based adaptation is required to achieve mathematical consistency.

Such adaptation has been conducted in post-cracking tension based on fracture mechanics. The authors followed logical procedures similar to those used for the post-peak analysis of tension and compression (An et al. 1997, Jansen 1995, 1997, Nakamura et al. 1999) and applied them to the fracture energy-based adaptation of the post-peak stress-strain relationship. Theoretically, this relationship can be computed in terms of the size of finite element by solving the constitutive relationships of the localized (loading state) and non-localized (unloading state) volume with the assumption of stress uniformity. As implicit nonlinear formulae are produced, the authors present an equivalent explicit-type computational formula in consideration of an easy and stable process of iterative computation. The original REV-based model features the damage evolution law (El-Kashif et al. 2003) given by

$$
d K=\left(\frac{\partial K}{\partial t}\right) \mathrm{dt}+\left(\frac{\partial K}{\partial \varepsilon_{e}}\right) \mathrm{d} \varepsilon_{e}
$$

The rate term of the fracture parameter denoted by $K$ in Eq. 2 was formulated in a past study (El-Kashif et al. 2003), and the second term of instantaneous evolution yields the following:

$$
\begin{aligned}
& \left(\frac{\partial K}{\partial \varepsilon_{e}}\right)=0 \quad \text { when } \mathrm{F}_{\mathrm{k}}>0 \\
& \left(\frac{\partial K}{\partial \varepsilon_{e}}\right)=-\left(\partial F_{k} / \partial \varepsilon_{e}\right) /\left(\partial F_{k} / \partial K\right) \text { when } \mathrm{F}_{\mathrm{k}}=0
\end{aligned}
$$



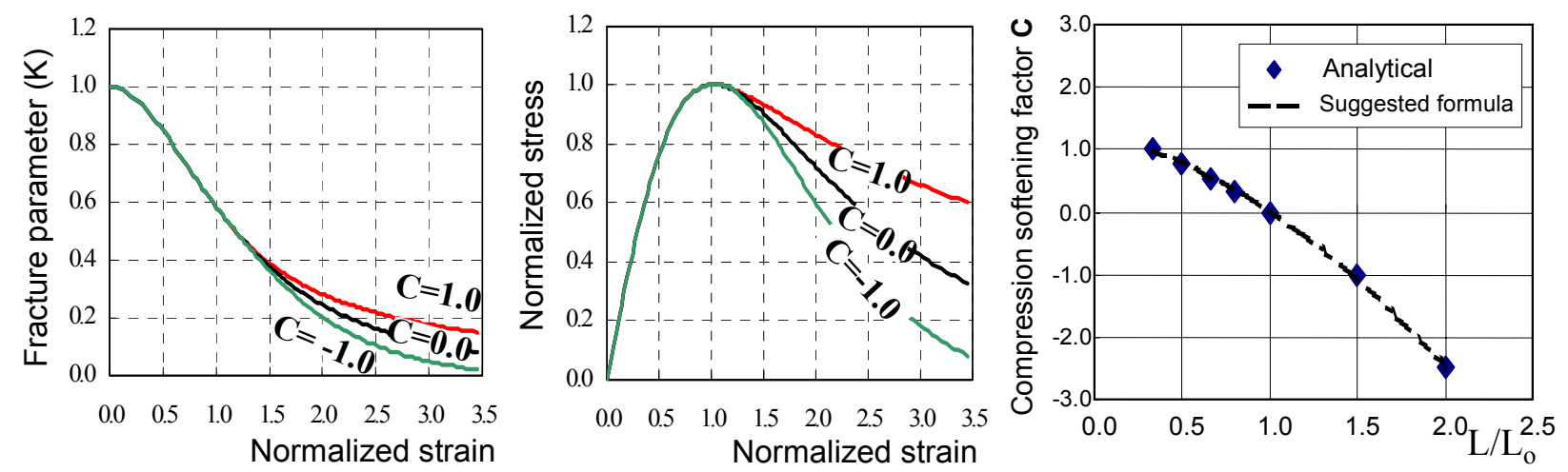

Fig. 9 Control parameter of compressive localization.
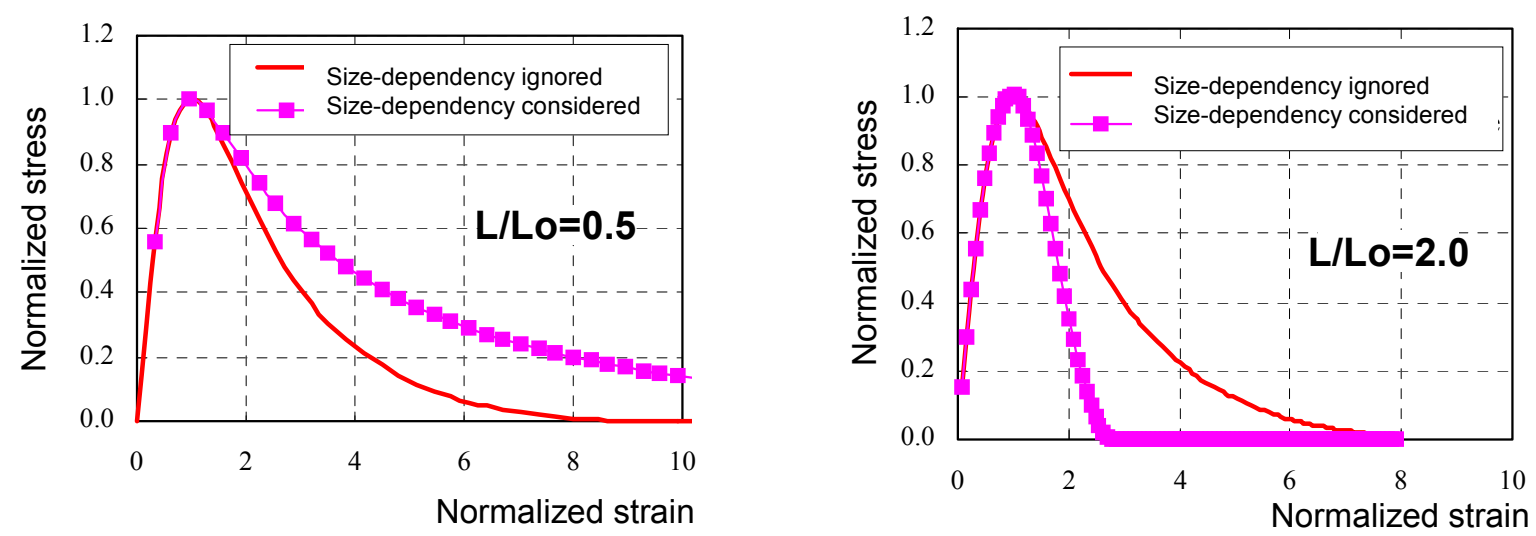

Fig. 10 Size-consistent stress-strain relationship.

For the original model corresponding to $\mathrm{REV}=20$ $\mathrm{cm}$, standard damage potential $F_{k}$ was proposed (Maekawa et al. 2003). In this study, this fracturing-related function was generalized to arbitrary REV with regard to the control index denoted by $C$ as,

$$
\begin{aligned}
& F_{k}=K-\exp \{-0.73 \beta(1-\exp (-1.25 \beta))\}, \\
& \beta=-\frac{1}{0.35}\left(\ln \left(1-\frac{7 \varepsilon_{\mathrm{e} c}}{20}\right)\right)
\end{aligned}
$$

where,

$$
\begin{aligned}
& \varepsilon_{e c}=\varepsilon_{e} \quad \text { if } \quad \varepsilon_{e}>=\mathfrak{R}, \\
& \varepsilon_{e c}=\varepsilon_{e} \quad \text { if } \varepsilon_{e}<\mathfrak{R} \\
& \mathfrak{R}=2.00-1.15 \gamma^{0.30}, \\
& \Omega=\left(0.75-0.87 \exp \left(-\varepsilon_{e} /(0.80 \Re)\right)^{C},\right. \\
& \gamma=\frac{\sigma_{c}}{\sigma_{c}+4 . \sigma_{l}}
\end{aligned}
$$

where, $\sigma_{\mathrm{c}}$ : uniaxial compressive strength, and $\sigma_{1}$ : lateral confining pressure. The stress-strain relationships given by Eq. (4) and Eq. (5) are shown in Fig. 9 according to the control index. The derivation process of these constitutive equations is explained below.

First, systematically arranged parametric studies were conducted with varied size of elements, loading rates and magnitude of confinement, and the resultant average stress-strain curves were obtained beforehand by using the original time-dependent constitutive equations. It was confirmed that the set of adapted curves shown in Fig. 9 was almost similar to the exact curve, which had been derived from the implicit iterative computation as stated above. This algebraic process of adaptation was conducted only to the part of fracture development, because the fracture parameter represented the internal continuum damage.

In order to specify parameter $C$, the authors assumed the constant specific fracture energy in compression (Lettsrisakulrat et al. 2000). To satisfy this we have,

$$
\begin{aligned}
& L_{o} \cdot G_{f}^{c}=L \cdot \int \sigma d \varepsilon \\
& L_{o} \int E_{o} K(C=0) \cdot\left(\varepsilon-\varepsilon_{p}\right) d \varepsilon \\
& \quad=L \int E_{o} K(C) \cdot\left(\varepsilon-\varepsilon_{p}\right) d \varepsilon
\end{aligned}
$$

where, $L_{o}$ : size of referential volume $(\mathrm{REV})$ as $20 \mathrm{~cm}, L$ : characteristic length of finite element, and $G_{f}$ : specific compressive fracture parameter. For integral with respect to strain above, the released energy in the ascending portion of stress-strain curve was extracted as a non-localized energy (see Fig. 8). The numerical solu- 


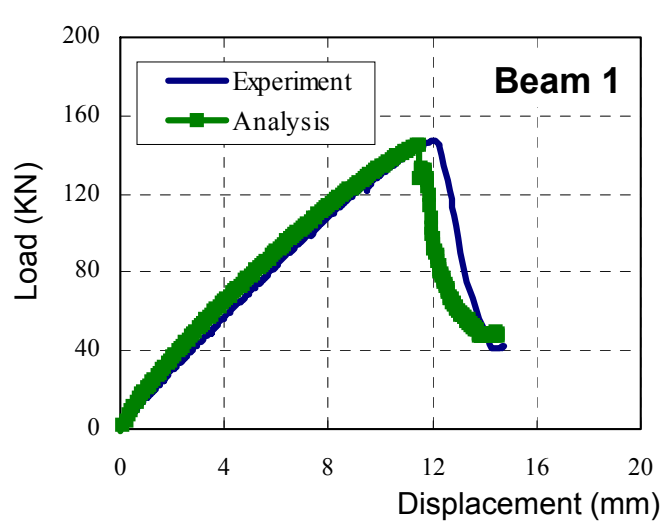

(a) Load versus displacement for Beam 1

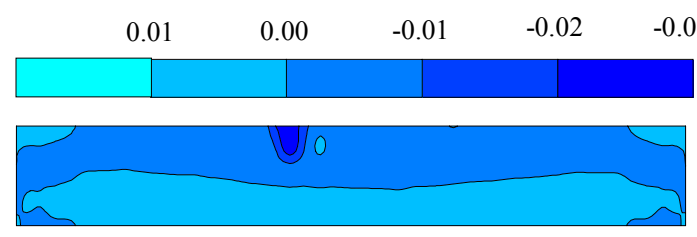

(c) Final horizontal strain distributions for Beam 1

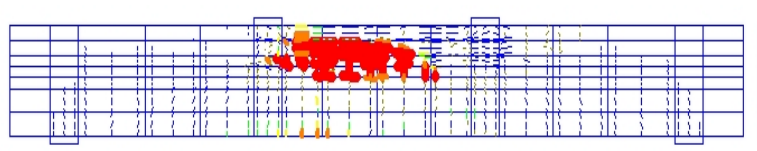

(e) Final crack pattern of Beam 1

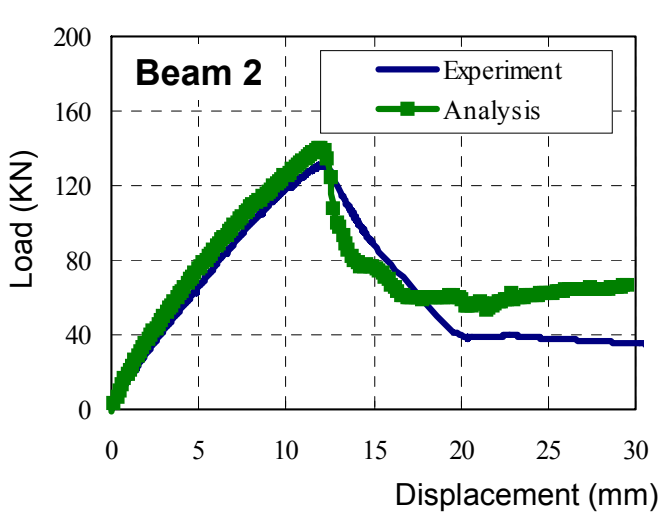

(b) Load versus displacement for Beam 2

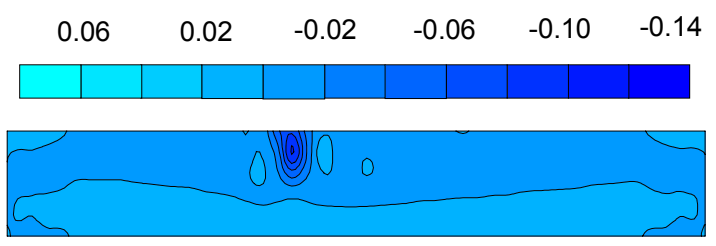

(d) Final horizontal strain distributions for Beam 2

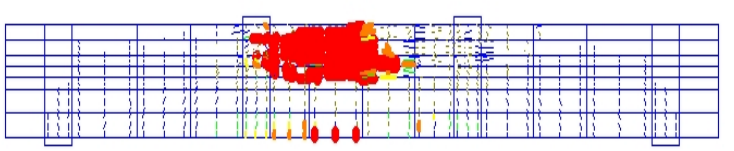

(f) Final crack pattern of Beam 2

Fig. 11 Computed post-peak displacement and deformation of unconfined RC beams (Time-dependency considered).

tion of Eq. (6) with regard to $C$ is shown in Fig. 9, and finally, the following equation was yielded:

$$
C=1.25-0.62\left[\frac{L}{L_{o}}\right]^{2}-0.63\left[\frac{L}{L_{0}}\right]
$$

For example, Fig. 10 shows the adapted average stress-strain curves for the different lengths of element. In the case where $L / L_{o}=1$, the ascending portion coincided with the original modeling. In the descending branch, the strain rate when softened compressive stress became almost zero was about half that in the standardized case where the descending branch was simplified down to a linear line. Conceptually this is the same as the modeling by Cervenka based on Van Mier's experimental facts (Van Mier 1986).

Confining the stress fields generally leads to stress deviation owing to the structural geometry and irregularity of the stress field, which may reduce the effectiveness of confinement. Pallewatta et al. (1995) proposed a confinement effectiveness index, which can be computed through full 3D nonlinear analysis to evaluate the mean stress-strain relationship of the confined concrete core (Maekawa et al. 2003). Based on these, the equivalent confining pressure applied to the constant moment zone was evaluated to be $2.2 \mathrm{MPa}$. The evaluated confining pressure was used for the internal pa- rameter ( $\gamma$ of Eq. 5) of the already verified time-dependent elasto-plastic and damaging model (El-Kashif et al. 2004).

\subsection{Loading rate effects on softened structural responses}

The computed and experimental results for unconfined members were compared, as shown in Fig. 11. Displacements at the loading points were assumed to be forced displacements in the analysis. The simulation of instant time dependency successfully captured structural behavior for both low and high loading rates, except for larger displacements of more than $20 \mathrm{~mm}$. Here, compressive reinforcement was laterally deformed in the buckling mode and the residual force after the development of compressive localization relied on the modeling of reinforcement under extreme deformation.

Figure 11 shows the trajectory of longitudinal compressive strain and cracking patterns. The thickness of crack indication lines corresponds to the tensile strain normal to the crack direction. The fictitious crack lines around the top compression fibers were indicated after the fulfillment of crack development criterion under biaxial compression-tension. As the RC beam was designed to possess a strong flexural mode as stated in Chapter 2, the crack orientation was almost parallel and normal to the member axis. Thus, the finite elements 


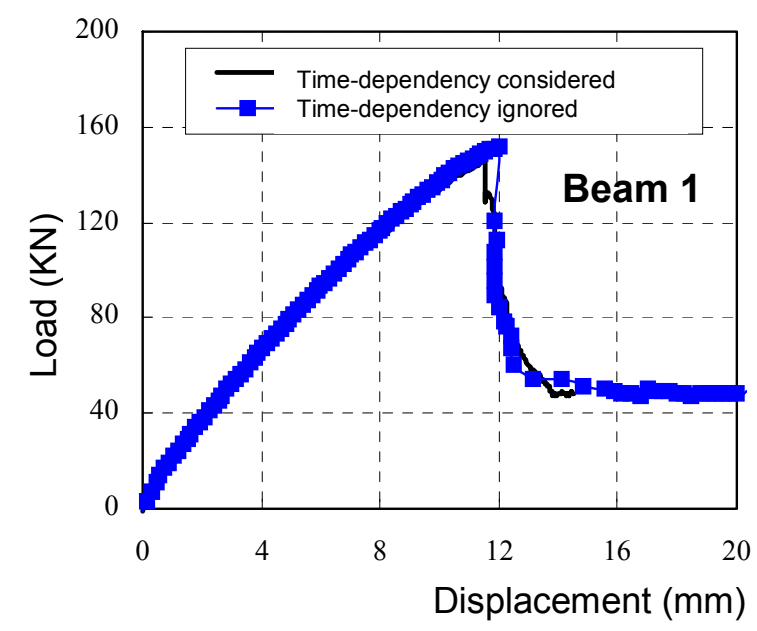

(a) Load versus displacement for Beam 1

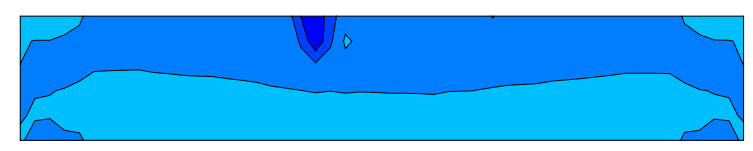

(c) Final horizontal strain distributions of Beam 1

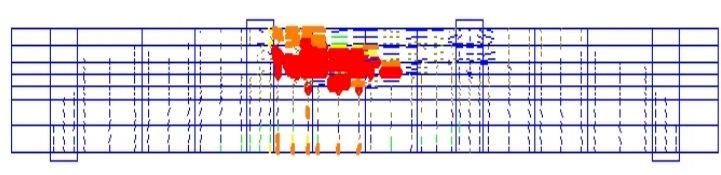

(e) Final crack pattern of Beam 1

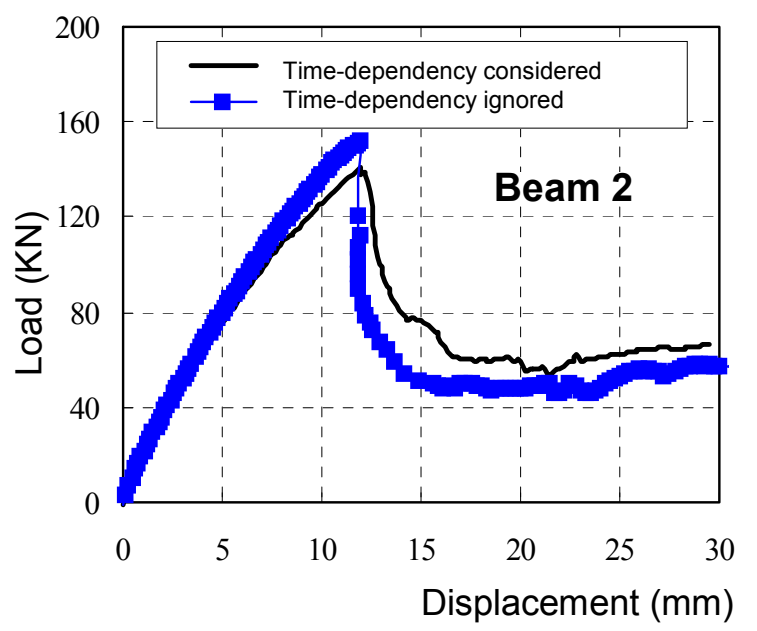

(b) Load versus displacement for Beam 2

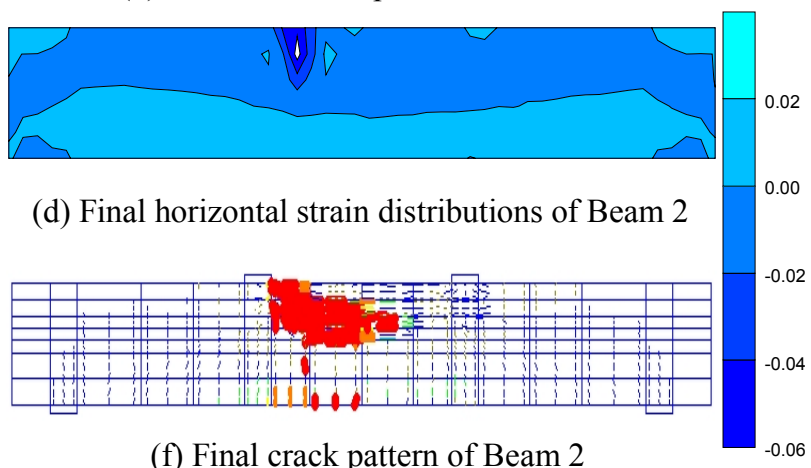

(f) Final crack pattern of Beam 2

Fig. 12 Computed post-peak displacement and deformation of unconfined RC beams (Time-dependency ignored).

may include cracking that is nearly parallel to their side-lines. Slightly different strain distributions in accordance with different loading rates were observed. In the case of a low loading rate, the localized strain area was slightly expanded as shown in Fig. 11, and the post-peak stress release became less pronounced than in the case of a high strain rate. These behavioral characteristics coincided with the previously mentioned facts.

A sensitivity analysis was performed by intentionally setting the time-dependent terms of plastic and damage evolutions to null. For the case of high rate loading, time-independent analysis yielded almost the same results as shown in Fig. 12. This means that the high loading rate created a rather small time-dependent evolution of nonlinearity. As discussed before, a small but substantial difference can be seen in the case of low rate loading.

The simulation results for confined beams were compared with the experimental results, as shown in Fig. 13. In the analysis, the effects of confinement on concrete in compression were well simulated in terms of ductility and stress decay in the post-peak region.

It must be noted that the computed size of the compressive localized zone was larger than that for unconfined members in both the high and low rates of loading. These results agreed with observed facts. In the experiments and analysis alike, the high loading rate created an apparent plastic plateau from 10 to $25 \mathrm{~mm}$ as well as a slightly higher flexural capacity followed by a sharp drop in residual force, as shown in Fig. 13. For the case of low loading rate, on the contrary, no clear plastic plateau was observed and the weak softening of structural post-peak responses followed. Time-dependent analysis may well simulate these behavioral characteristics. In analytical terms, the low rate of loading brought about an expanded localized zone where damage continued to evolve, which agrees with reality.

To investigate the effect of time-dependent evolution of concrete nonlinearity, sensitivity analysis was conducted to cut off the term of time dependency, as shown in Fig. 14. Compared with the low rate of loading, the time dependency of the post-peak response was clearly identified, although the pre-peak behavior was hardly affected. On the whole, the softened rate of residual force became larger when time dependency was ignored. In the case of a high loading rate, there were certain differences from the time-independent analysis. The release rate of residual force was almost similar but the apparent plastic plateau was different. In the time-independent analysis, the intensity of localization was somewhat small. It can be said that considering the time dependency of material nonlinearity had a more significant impact on the confined concrete analysis. To further explore the effect of time on localization phenomena, local straining is discussed quantitatively in the next section. 


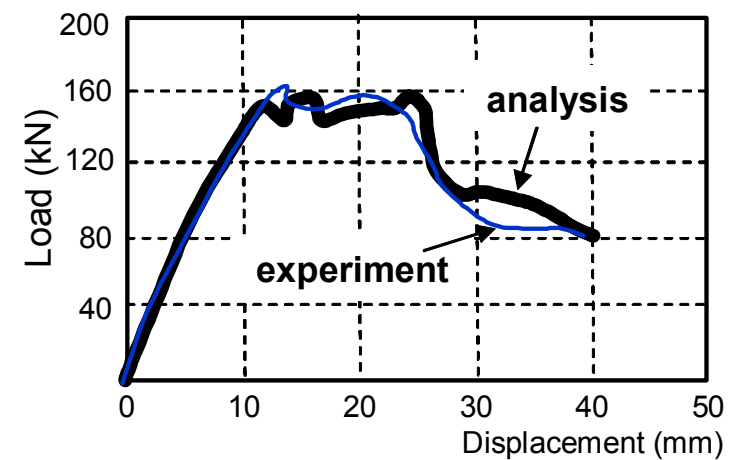

(a) Load versus displacement for Beam 3

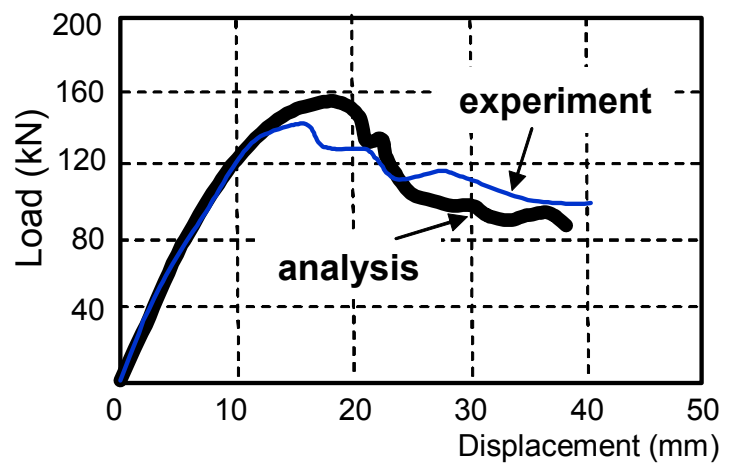

(b) Load versus displacement for Beam 4

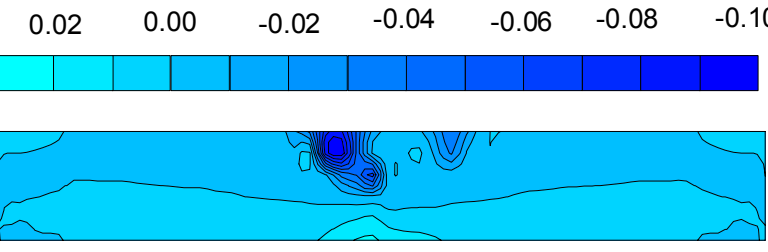

(c) Final horizontal strain distributions of Beam 3

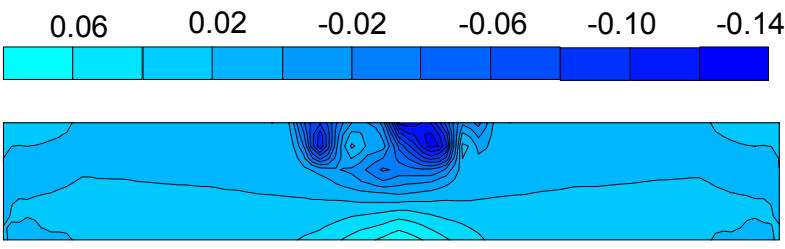

(d) Final horizontal strain distributions of Beam 4

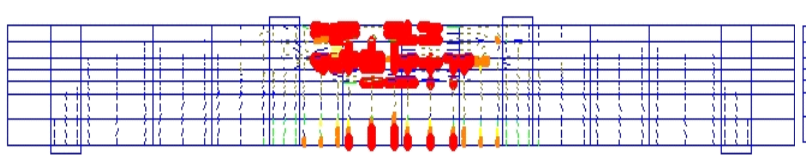

(e) Final crack pattern of Beam 3

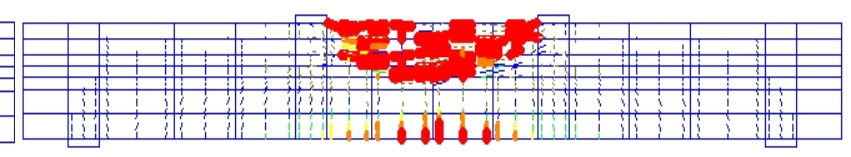

(f) Final crack pattern of Beam 4

Fig. 13 Computed post-peak displacement and deformation of confined RC beams (Time-dependency considered).

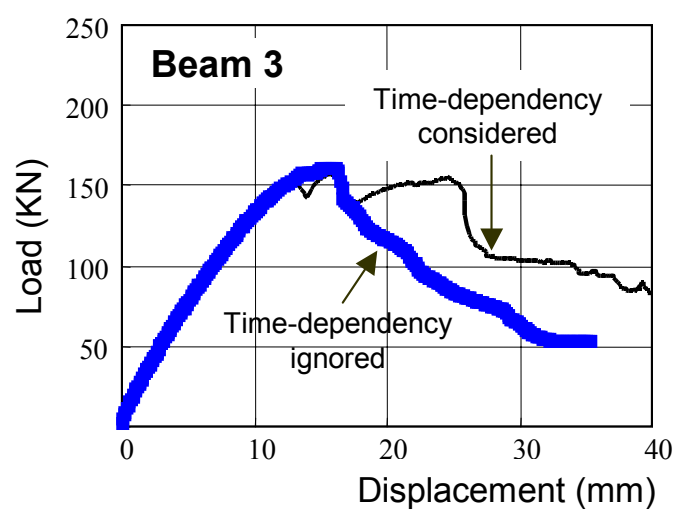

(a) Load versus displacement of Beam 3

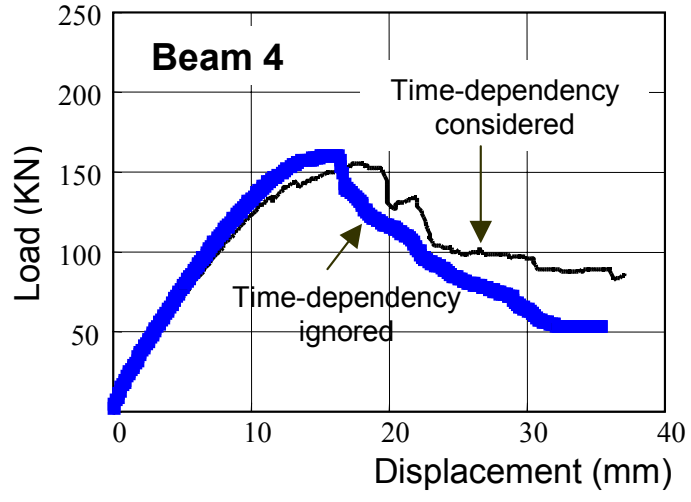

(b) Load versus displacement of Beam 4

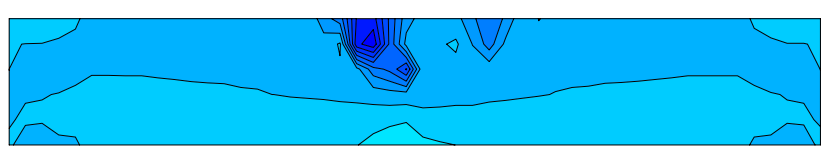

(c) Final horizontal strain distributions of Beam 3

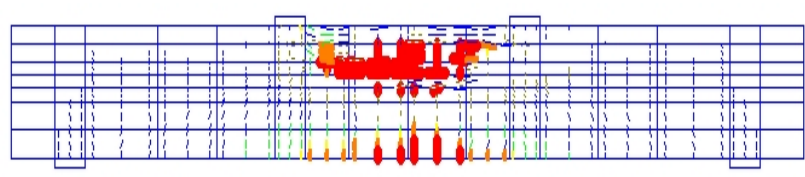

(d) Final crack pattern of Beam 3

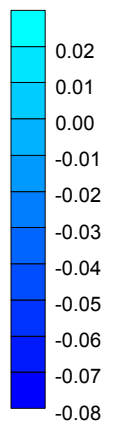

$-0.08$

Fig. 14 Computed post-peak displacement and deformation of confined RC beams (Time-dependency ignored). 

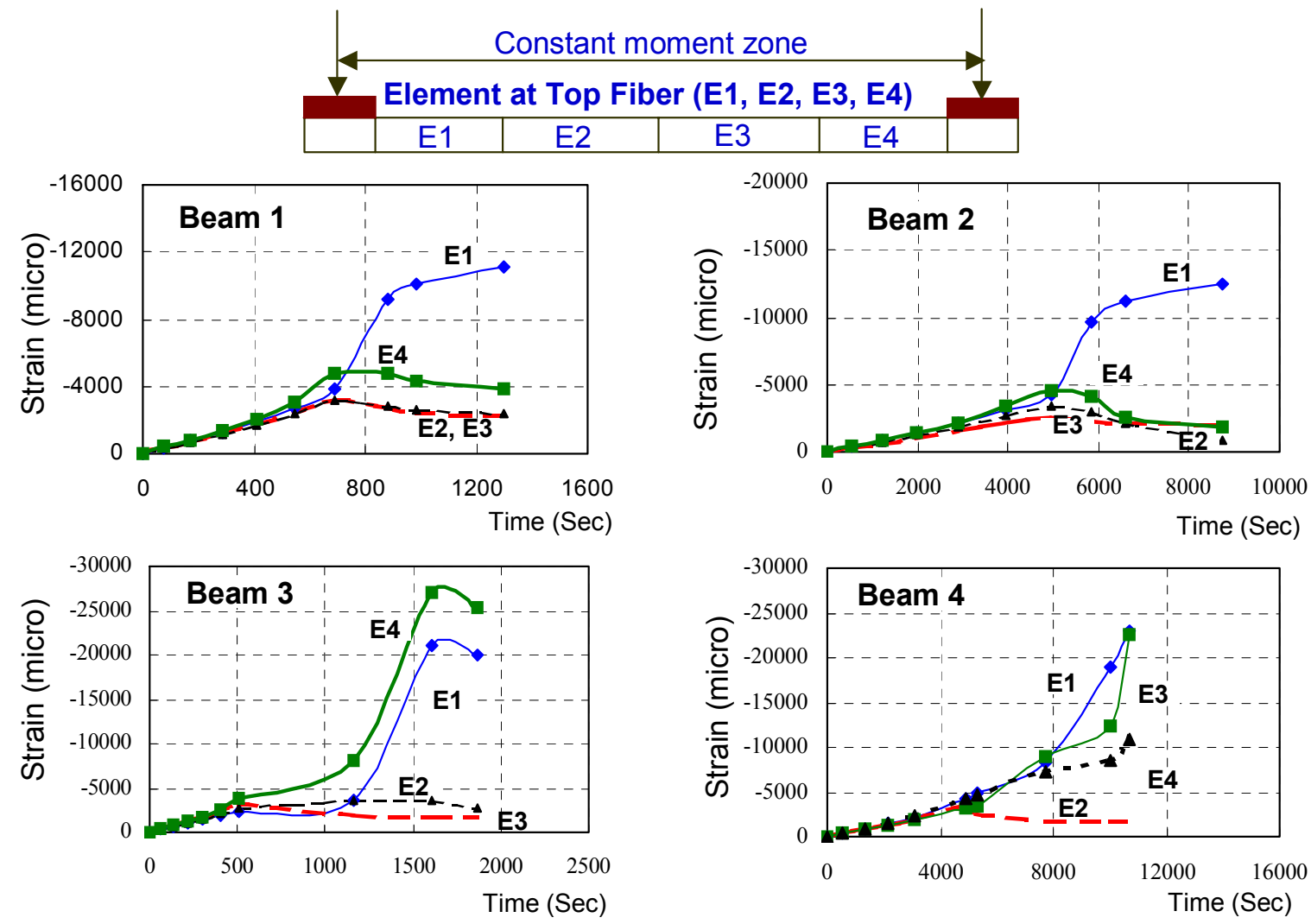

Fig. 15 Computed localized average strains in finite elements $(20 \mathrm{~cm})$.

3.4 Loading rate effect on localized deformation Figure 15 shows the relationship between the strains and elapsed time in each finite element. The strain values here were space-averaged over individual finite elements, which were placed on a span of constant bending moment. The normal strain component along the member axis was focused on. Because the element size was not exactly the same as the length of embedded strain gauges, strictly speaking, the computation results shown in Fig. 15 cannot be compared with the data shown in Fig. 6. Still, approximate checking is possible.

In all cases, one element $(20 \mathrm{~cm})$ bore evidence of a high deformational rate, and roughly speaking, localized strain showed similar values to those in the experiments shown in Fig. 6. In the case of unconfined beams, other elements changed to the unloading state where no instantaneous evolution of plasticity and damaging took place regardless of the rate of loading. On the other hand, two or three elements $(40$ to $60 \mathrm{~cm}$ ) displayed a rapid increase in strain. This means that the strain localization zones expanded where lateral confinement was provided, and is consistent with the experimental observation. Figure 16 shows the relationship between computed force and local strains in the finite elements placed over the span center of the beams, which can be compared with the experimental results shown in Fig. 7. Roughly speaking, the relationship between softening force and the corresponding local strain was similar to the experiment. The computed damage zones of confined beams were widely extended unlike the unconfined beams. In the post-peak-capacity process, some elements were found to change to the unloaded condition after showing higher deformation than the peak strain born by the compressive strength of concrete.

In the analysis of unconfined beams, strain values at the peak load were not uniform but indicated scattering of about $20 \%$ where the experimentally observed displacements were induced at the loading points. This scattering was caused by the presence of bearing plates. The stress concentration occurred close to the loading plates and supplementary strain progress, which triggered localization, was observed. But in reality, as the bearing plates provided friction-based $3 \mathrm{D}$ confinement in the direction of breadth, the stress concentration was lowered. This $3 \mathrm{D}$ effect was not taken into account in the $2 \mathrm{D}$ analysis. For the analysis of confined beams, the local effect of bearing plates was small due to the ductile material properties assumed in the constitutive model.

\subsection{Stress-strain relation of structural concrete}

Since time dependency was considered in the general constitutive law used in the analysis here, the resultant stress-strain relationship developed inside the structures was not unique but dependent on time and location. Given this, the authors extracted the actualized stress-strain paths of structural concrete at the span center along the member axis, as shown in Fig. 17, which 

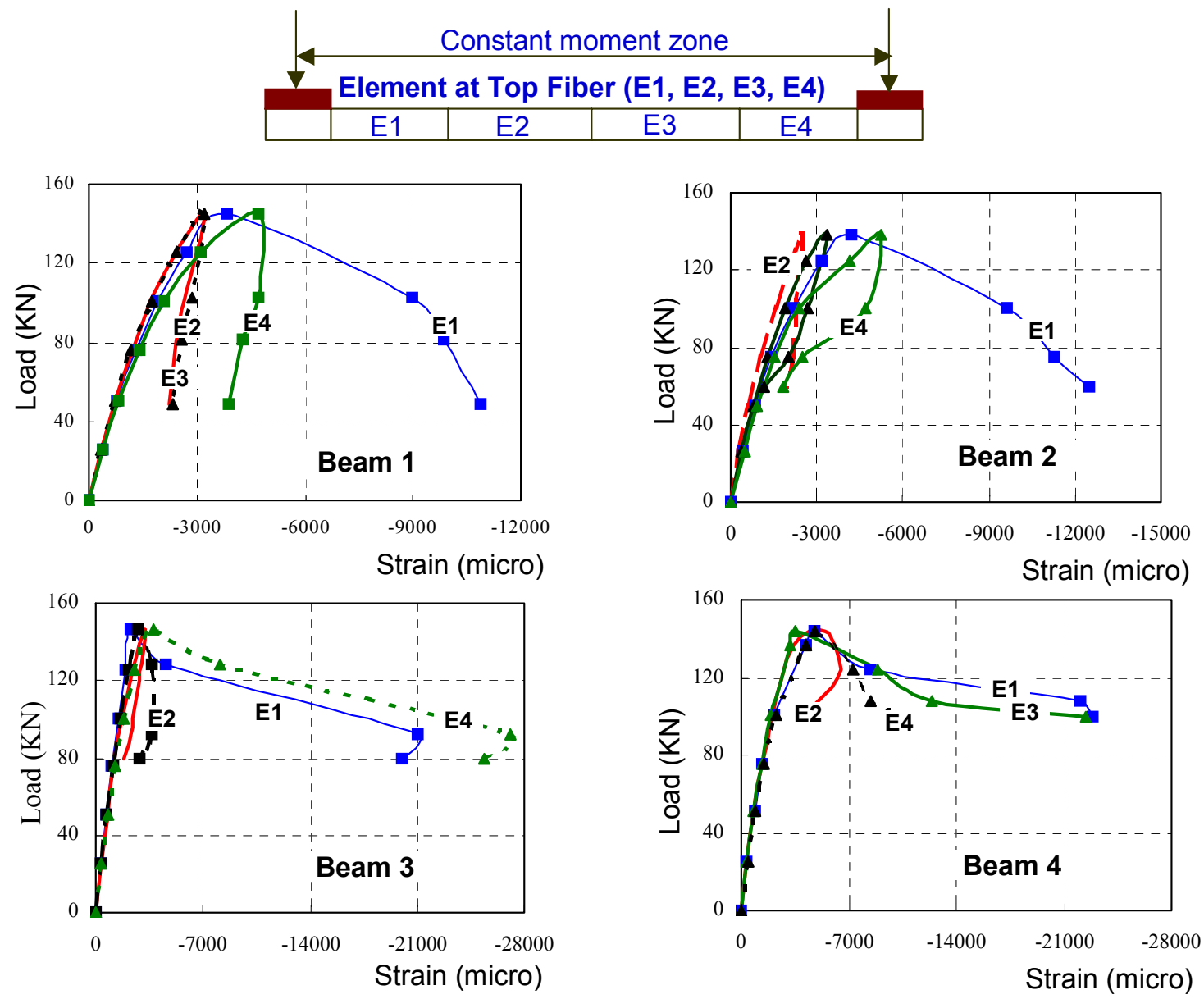

Fig. 16 Relationships between computed force and local strain in each element $(20 \mathrm{~cm})$.
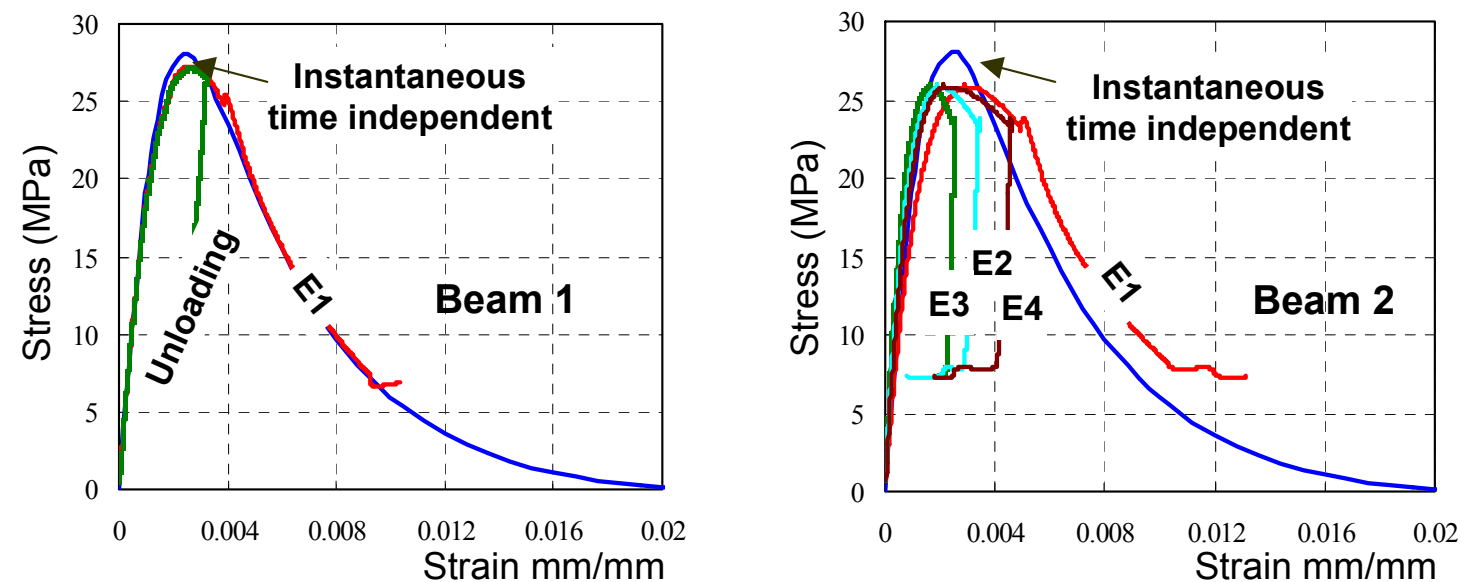

Fig. 17 Stress-strain curves for unconfined beams along constant moment span at the top fiber.

illustrates the case of unconfined beams. For higher loading rates, the stress-strain relationship developed at the strain-localized element was almost the same as that of the time-independent modeling. Other finite elements indicated unloading paths. These results indicate that for high loading rates of unconfined concrete, it is possible to apply a time-independent- unique stress-strain relationship in compression and perform reasonable post-peak analysis.
Under the low rate of loading, however, the resultant stress-strain relationship was not unique, as shown in Fig. 17. This was caused by the different strain rates produced at each location, which accompanied strain localization. Here, careful attention should be given to the post-peak process. Although the external loading rates were very different, the slope of the descending branch of $E 1$ was almost the same as that of E1 in Fig. 17. The stiffness of unloading condition was also similar 

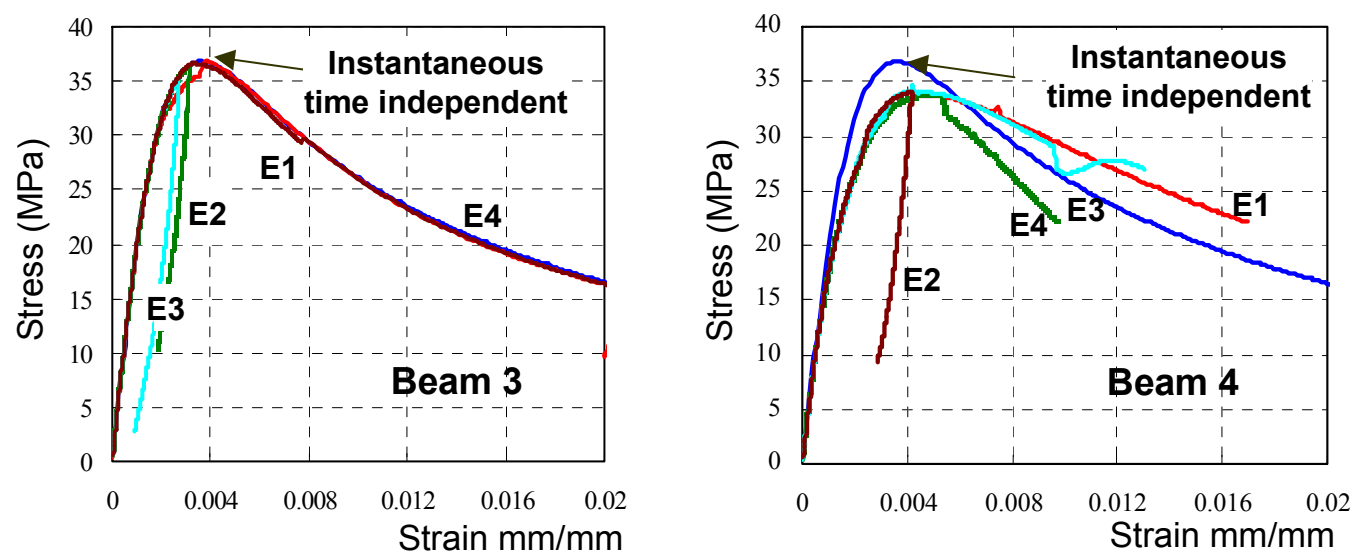

Fig. 18 Stress-strain curves for cnfined beams along constant moment span at the top fiber.
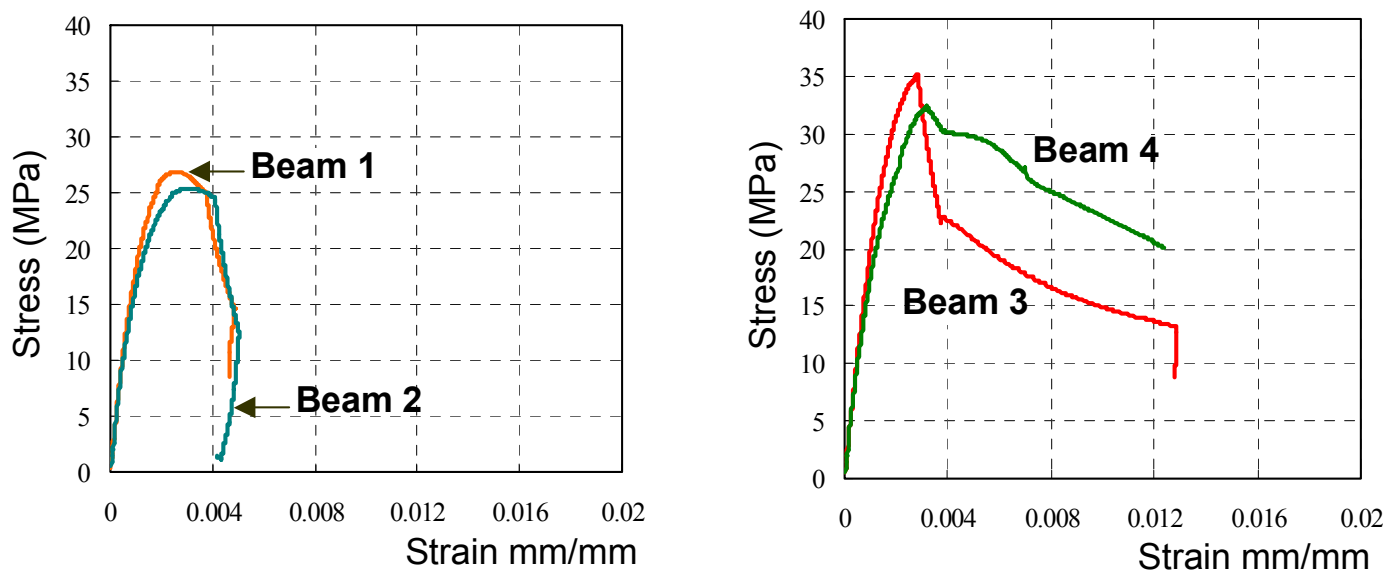

Fig. 19 Extracted average stress strain relationship over full center span of the beams.

to that of the high loading rate regardless of the loading rate. It is the local strain rate that is at issue here. Immediately after the initiation of localization, the strain rate under the loading and unloading conditions suddenly increased despite the small rate of external displacement. The incremental stress-strain relationship became equivalent to that of the time-independent modeling. It can be concluded that without the time-dependent modeling, the post-peak structural behavior can consequently be simulated due to the fact that strain localization inevitably leads to high strain rates and removes the time-dependent plasticity and damage accumulated in the past mechanical history.

The resultant stress-strain relationships of confined $\mathrm{RC}$ beams are shown in Fig. 18. It can be seen that the high loading rate hardly produced time-dependent nonlinearity at any location. In contrast, the stress-strain curves developed along the axis of member varied in accordance with locations under the low loading rate. The softening region of the curves deviated from the instantaneous envelope, and the slope of descending parts was not parallel to the instantaneous slope unlike the unconfined beams. The time-dependent effect in the past hysteresis did not disappear but remained in the post-peak regions. Thus, the time-dependent constitutive model is required to enhance the accuracy of post-peak analysis.

As discussed before, the time dependency of material mechanics affects the local stress-strain relationship of structural concrete as well as the volume of strain-localized zone. These two factors had much to do with the structural post-peak behaviors. The average stress-strain relationships of concrete between the two loading supports, which are the result of two factors affected by the loading rate, are shown in Fig. 19.

The averaged stress-strain relationship at the top fiber was not pronouncedly time-dependent in the case of unconfined beams $(1,2)$, while it was significantly time-dependent in the case of confined beams $(3,4)$. In view of RC structural mechanics, the time dependency in the post peak region carries greater weight in the practice of collapse analysis.

\section{Conclusions}

To investigate the rate effect on the post-peak structural behaviors associated with compression softening, experimental and analytical studies were performed on over-reinforced concrete beams with and without confinement under flexure with different rates of loading, which gave the following insights: 
(1) The experimental results of over-reinforced concrete beams indicated that the flexural softening of $\mathrm{RC}$ members was time-dependent and ductility was affected by the loading rate and the confining pressure caused by stirrups.

(2) The compressive strain distributions in constant moment zones were found to be almost uniform before the peak load, but after the peak, strain started becoming localized and a softening branch was observed. Here, high loading rates showed a sharper decay of residual force in the softening branch, unlike lower loading rates.

(3) By introducing a confining pressure to structural concrete as well as longitudinal reinforcement in constant moment zones, the flexural softening of $\mathrm{RC}$ beams was stabilized and its effects on the softening of load-displacement relations were comparatively intensified.

(4) The pre- and post-peak time-dependent constitutive modeling for plasticity and fracturing of concrete was verified in structural members. It was examined just under the constant stress fields using specimens. The explicit time-dependent constitutive model was incorporated into the structural analysis program to verify the constitutive model, and numerical stability was examined. The time-dependent behaviors of concrete beams were fairly well simulated by this modeling.

(5) The time dependency of structural concrete should be considered for improved post-peak simulation, especially for over-reinforced and/or confined RC members in flexure.

\section{Acknowledgments}

The authors appreciate fruitful and valuable discussion with Dr. T. Ishida and Dr. T. Kishi of The University of Tokyo. This study was financially supported by Grant-in-Aid for Scientific Research (S) No.15106008.

\section{References}

Alca, N., Alexander, S. D. B. and MacGregor, J. G. (1997). "Effect of size on flexural behavior of high strength concrete beams." ACI Structural Journal, 94(1), 59-67.

An, X., Maekawa, K. and Okamura, H. (1997). "Numerical simulation of size effect in shear strength of RC beams." Journal of Materials, Concrete Structures and Pavement, JSCE, V-35(564), 297-316.

Cervenka, V. and Cervenka, J. "Computer simulation as a design tools for concrete structures." ICCE-96, Bahrain.

Dhakal, R. P. and Maekawa, K. (2002). "Modeling for post-yield buckling of reinforcement bar including buckling." Journal of Structural Engineering, ASCE, 128(9), 1139-1147.

El-Kashif, K. F. and Maekawa, K. (2004). "Time-dependent nonlinearity of compression softening in concrete." Journal of Advanced Concrete Technology, Japan Concrete Institute, 2(2), 233-247.

El-Kashif, K. F. and Maekawa, K. (2003). "Computational model for time-dependent compressive behavior based on plasticity and fracturing approach." JCI Proceedings, 25(2), 145-150.

El-Kashif, K. F. and Maekawa, K. (2003). "Time-dependent compressive deformation and post-peak softening for concrete." Toronto, Conference on Response of Structures to Extreme Loading.

Jansen, D. C., Shah, S. P. and Rossow, E. C. (1995). "Stress-strain results of concrete from circumferential strain feedback control testing." ACI Material Journal, 92(4), 419-428.

Jansen, D. and Shah. S. P. (1997). "Effect of length on compressive strain softening of concrete." Journal of Engineering Mechanics, ASCE, 123(1), 25-35.

Lettsrisakulrat, T., Watanabe, K., Matsuo, M. and Niwa, J. (2000). "Localization effects and fracture mechanism of concrete in compression." JCI Proceedings, 22(3), 145-150.

Maekawa, K. and El-Kashif, K. F. (2004). "Cyclic cumulative damaging of reinforced concrete in post-peak regions." Journal of Advanced Concrete Technology, Japan Concrete Institute, 2(2), 257-271.

Maekawa, K, Pimanmas, A. and Okamura, H. (2003). "Nonlinear Mechanics of Reinforced Concrete." SPON Press, London.

Nakamura, H. and Higai, T. (1999). "Compressive fracture energy and fracture zone length of concrete." Seminar on Post-peak Behavior of RC Structures Subjected to Seismic Loads, Japan Concrete Institute, C51E(2), 259-272.

Okamura, H. and Maekawa, K. (1991). "Nonlinear Analysis and Constitutive Model of Reinforced Concrete." Giho-do Press, Tokyo.

Pallewatta, T. M., Irawan, P. and Maekawa, K. (1995). "Effectiveness of laterally arranged reinforcement on the confinement of core concrete." Proc. of JSCE, V-28(520), 297-308.

Van Mier, J. G. M. (1986). "Multiaxial strain-softening of concrete, Part I: Fracture.” Material and structures, RILEM, 19(111), 179-190.

Weiss, J., Kadir, G. and Shah, S. P. (2001). "Localization and size-dependent response of reinforced concrete beams." ACI Structural Journal, 98(5), 686-695. 